\title{
Self-reported symptoms of schizotypal and borderline personality disorder in patients with mood disorders
}

\section{Baryshnikov, I.}

2016-03

Baryshnikov , I , Suvisaari , J , Aaltonen , K, Koivisto , M , Naatanen , P , Karpov , B , Melartin , T , Oksanen , J , Suominen , K , Heikkinen, M , Paunio , T , Joffe , G \& Isometsa , E 2016 , ' Self-reported symptoms of schizotypal and borderline personality disorder in patients with mood disorders ' , European Psychiatry , vol. 33 , pp. 37-44 . https://doi.org/10.1016/j.eurpsy.2015.12.0

http://hdl.handle.net/10138/223888

https://doi.org/10.1016/j.eurpsy.2015.12.006

publishedVersion

Downloaded from Helda, University of Helsinki institutional repository.

This is an electronic reprint of the original article.

This reprint may differ from the original in pagination and typographic detail.

Please cite the original version. 
Original article

\title{
Self-reported symptoms of schizotypal and borderline personality disorder in patients with mood disorders
}

\author{
I. Baryshnikov ${ }^{\text {a,1 }}$, J. Suvisaari ${ }^{\text {a,b }}$, K. Aaltonen ${ }^{\text {a,c,1 }}$, M. Koivisto ${ }^{\text {a }}$, P. Näätänen ${ }^{\text {a }}$, B. Karpov ${ }^{\text {a }}$, \\ T. Melartin $^{\mathrm{f}, 2}$, J. Oksanen ${ }^{\mathrm{b}}$, K. Suominen ${ }^{\mathrm{d}, \mathrm{e}, 3}{ }$, M. Heikkinen $^{\mathrm{a}}$, T. Paunio ${ }^{\mathrm{a}}$, \\ G. Joffe ${ }^{a}, E$. Isometsä ${ }^{a, c, *}$ \\ ${ }^{a}$ Department of Psychiatry, University of Helsinki and Helsinki University Hospital, P.O. Box 22, (Välskärinkatu 12 A), 00014 Helsinki, Finland \\ ${ }^{\mathrm{b}}$ Department of Social Services and Health Care, Helsinki, Finland \\ ${ }^{\mathrm{c}}$ National Institute for Health and Welfare, Mental Health Unit, Mannerheimintie 166, 00271 Helsinki, Finland \\ d City of Helsinki, Social Services and Healthcare, Helsinki, Finland \\ e Aurora Hospital, P.O. Box 6800, 00099 Helsinki, Finland \\ ${ }^{\mathrm{f}}$ Department of Psychiatry, University of Helsinki and Helsinki University Hospital, P.O. Box 590, 00029 Helsinki, Finland
}

\section{A R T I C L E I N F O}

\section{Article history:}

Received 27 November 2015

Received in revised form 21 December 2015

Accepted 23 December 2015

Available online 6 February 2016

\section{Keywords:}

Borderline Personality Disorder

Schizotypal Personality Disorder

McLean Screening Instrument

Schizotypal Personality Questionnaire Brief

\begin{abstract}
A B S T R A C T
Background: Distinguishing between symptoms of schizotypal (SPD) and borderline personality disorders (BPD) is often difficult due to their partial overlap and frequent co-occurrence. We investigated correlations in self-reported symptoms of SPD and BPD in questionnaires at the levels of both total scores and individual items, examining overlapping dimensions.

Methods: Two questionnaires, the McLean Screening Instrument (MSI) for BPD and the Schizotypal Personality Questionnaire Brief (SPQ-B) for SPD, were filled in by patients with mood disorders $(n=282)$ from specialized psychiatric care in a study of the Helsinki University Psychiatric Consortium. Correlation coefficients between total scores and individual items of the MSI and SPQ-B were estimated. Multivariate regression analysis (MRA) was conducted to examine the relationships between SPQ-B and MSI.

Results: The Spearman's correlation between total scores of the MSI and SPQ-B was strong (rho $=0.616$, $P<0.005)$. Items of MSI reflecting disrupted relatedness and affective dysregulation correlated moderately $\left(r_{\varphi}\right.$ varied between 0.2 and $\left.0.4, P<0.005\right)$ with items of SPQ. Items of MSI reflecting behavioural dysregulation correlated only weakly with items of SPQ. In MRA, depressive symptoms, sex and MSI were significant predictors of SPQ-B score, whereas symptoms of anxiety, age and SPQ-B were significant predictors of MSI score.

Conclusions: Items reflecting cognitive-perceptual distortions and affective symptoms of BPD appear to overlap with disorganized and cognitive-perceptual symptoms of SPD. Symptoms of depression may aggravate self-reported features of SPQ-B, and symptoms of anxiety features of MSI. Symptoms of behavioural dysregulation of BPD and interpersonal deficits of SPQ appear to be non-overlapping.
\end{abstract}

(c) 2016 Elsevier Masson SAS. All rights reserved.

\section{Introduction}

The relationship between borderline personality disorder (BPD) and schizotypal personality disorder (SPD) is complicated and has been a subject of debates for years [1-3]. In the Diagnostic and

\footnotetext{
* Corresponding author. Department of Psychiatry, University of Helsinki, P.O. Box 22, (Välskärinkatu 12 A), 0014 Helsinki, Finland. Tel.: +358 9 4711; fax: +358 947163735 .

E-mail address: erkki.isometsa@hus.fi (E. Isometsä).

1 Tel.: +35894711.

2 Tel.: +3589 4711; fax: +358947163735.

3 Tel.: +358407718354
}

Statistical Manual of Mental Disorder III-R (DSM-III-R), the broad construct "borderline disorders" was separated into BPD and SPD [4]. Genetic, neurobiological and phenomenological associations of SPD with schizophrenia-related psychopathology [5] and BPD with affective disorders underlined this distinction [2,6,7]. Nevertheless, numerous studies indicate that the disorders frequently co-occur and both are often co-morbid with affective disorders [8-12].

The essential features of SPD are reduced capacity for close relationships, cognitive or perceptual distortions and eccentricities of behaviour $[13,14]$. In contrast, patients with BPD suffer from instability of interpersonal relationships, self-image, and affects, and marked impulsivity [14]. However, despite apparently distinct features, differential diagnosis between BPD and SPD is often 
difficult due to commonly acknowledged partial phenomenological overlap of their symptoms and frequent co-occurrence of their dimensions [10,14-18]. The features of BPD and SPD are recognized to often co-exist also at a subclinical level in general populations $[13,15,19]$. Moreover, high co-occurrence of traits of both personality disorders have also been reported in mood disorder patients [20-22].

Many studies indicate significant negative effects of co-morbid personality disorder on course and emotional and social functioning of patients with mood disorders [22-24]. However, a factor potentially complicating measurement of personality traits is the influence of current depressive, anxiety and other such symptoms [25-28]; depressive symptoms, in particular, are known to often aggravate measures of neuroticism. This probably renders the reliability of self-reported features of personality disorders by patients with mood and anxiety disorders somewhat uncertain. Nonetheless, it is clinically important to recognize features of BPD and SPD in patients with mood disorders, and it is essential to distinguish them in patients with mood disorders because of noticeable differences in their management [29-31].

Overall, numerous studies have underlined the importance of detecting traits of SPD [32] and BPD [33]. Clinically relevant personality traits are usually evaluated by clinical interviewing [33], but use of self-reported scales may improve their recognition [34]. The McLean Screening Instrument (MSI) is a useful and valid screening tool created to detect dimensions of BPD [35,36]. MSI is based on self-reported symptoms, derived from DSM-IV diagnostic criteria of BPD. The Schizotypal Personality Questionnaire Brief (SPQ-B) is a useful instrument constructed to assess features of SPD, derived from DSM-III-R diagnostic criteria of BPD [37]. To our knowledge, this is the first study to examine the relationships of these questionnaires.

In our study, we aimed to investigate the relationships of selfreported features of SPD and BPD in patients with mood disorders. We hypothesized, that partial overlap of BPD and SPD constructs may be observed also on the level of self-reported traits of BPD and SPD. These characteristic overlapping and non-overlapping items could help clinicians to distinguish disorders clinically. Therefore, we examined correlations of total scores of MSI and SPQ-B, and factors that probably influence the prevalence of observed features of BPD and SPD. To pinpoint overlapping and non-overlapping symptoms of SPD and BPD, we conducted correlation analysis at the level of both scale dimensions and separate items.

\section{Methods}

The Helsinki University Psychiatric Consortium (HUPC) study design, setting and patient sampling processes are presented in more detail elsewhere [38], but are briefly outlined below.

\subsection{The Helsinki University Psychiatric Consortium (HUPC)}

This investigation is a part of the HUPC study, a collaborative research project between the Faculty of Medicine of the University of Helsinki; the Department of Mental Health and Substance Abuse Services of the National Institute for Health and Welfare; the Department of Social Services and Health Care, City of Helsinki; and the Department of Psychiatry, University of Helsinki and Helsinki University Hospital. The study protocol was approved by the Ethics Committee of Helsinki University Central Hospital.

\subsection{Setting}

The study was conducted in 10 community mental health centres, three psychiatric inpatient units and one day-hospital offering specialized secondary public mental health services in the metropolitan area of Helsinki between 12.1.2011 and 20.12.2012.

\subsection{Sampling}

Inclusion criteria were patients' age of over 18 years and provision of informed consent. Patients with mental retardation, neurodegenerative disorders and insufficient Finnish language skills were excluded. Stratified patient sampling selection was performed by identifying all patients within a certain day or week in a unit or by randomly drawing eligible patients from patient lists. Patients treated for psychotic disorders, neuropsychiatric disorders, anxiety disorders, eating disorders, BPD, or substance use disorders as lifetime principal diagnosis were excluded from this study. Of the 902 eligible patients with mood, neurotic or personality disorders, 372 refused to participate and 216 were lost for other reasons.

\subsection{Clinical diagnoses}

The validity of the clinical diagnoses assigned by the attending physicians was critically evaluated by the authors (IB, KA, MK, BK) by re-examining all available information from patient records. Authors KA, IB and BK were residents of psychiatry trained in diagnostic evaluations; in any unclear cases, the senior psychiatrists ( $\mathrm{MK}, \mathrm{EI}, \mathrm{GJ}, \mathrm{MH}$ ) were consulted. The validated clinical diagnoses were based on the ICD-10-DCR [39]. Lifetime principal diagnosis was assigned. Although there is no division of $\mathrm{BD}$ into types I (BD-I) and II (BD-II) in the ICD-10, we subtyped patients into these categories according to the DSM-IV [40]. This distinction is established clinical practice in Finland and included in the national BD treatment guidelines.

\subsection{Description of patients}

Altogether 282 patients participated in the study. Their mean age was $42.2 \pm 13.1$ years, and 209 (74.1\%) were female. All patients were allocated into groups according to the lifetime clinical principal diagnosis (Table 1). Patients comprised those with depressive episode (F32-F33; unipolar depression [MDD] $[n=183$; mean age $41.4 \pm 13.3$ years]), bipolar disorder (BD) (F31; $n=99$, mean age

Table 1

Characteristics of SPQ-B and MSI responders $(n=282)$.

\begin{tabular}{|c|c|c|c|c|c|c|}
\hline & \multicolumn{2}{|l|}{$\mathrm{BD}$} & \multicolumn{2}{|l|}{ MDD } & \multicolumn{2}{|l|}{ Total } \\
\hline & $n$ & $\%$ & $n$ & $\%$ & $n$ & $\%$ \\
\hline Number & 99 & 35 & 183 & 65 & 282 & 100 \\
\hline Age $($ mean $\pm S D)$ & $43.7 \pm 12.7$ & & $41.4 \pm 13.3$ & & $42.3 \pm 13$ & \\
\hline Sex (male) & 36 & 36.3 & 42 & 22.9 & 78 & 27.7 \\
\hline \multicolumn{7}{|l|}{ Marital status } \\
\hline Married & 20 & 20.2 & 39 & 21.3 & 59 & 21 \\
\hline Cohabitation & 17 & 17.2 & 29 & 15.8 & 46 & 16.3 \\
\hline Unmarried & 32 & 32.2 & 75 & 41 & 107 & 38.2 \\
\hline Divorced & 29 & 29.3 & 35 & 19.1 & 64 & 22.7 \\
\hline Widowed & 1 & 1 & 3 & 1.7 & 4 & 1.4 \\
\hline \multicolumn{7}{|l|}{ Work status } \\
\hline $\begin{array}{l}\text { Retired due to } \\
\text { mental disorder }\end{array}$ & 37 & 37.4 & 23 & 12.5 & 60 & 21.2 \\
\hline Unemployed & 10 & 10 & 18 & 9.8 & 28 & 9.9 \\
\hline Sick leave & 22 & 22.2 & 64 & 35 & 86 & 30.5 \\
\hline $\begin{array}{l}\text { Retired for another } \\
\text { reason }\end{array}$ & 1 & 1 & 8 & 4.4 & 9 & 3.2 \\
\hline Student & 7 & 7.1 & 24 & 13.1 & 31 & 10.9 \\
\hline Employed & 20 & 20.2 & 30 & 16.4 & 50 & 17.7 \\
\hline $\begin{array}{l}\text { Unemployed for } \\
\text { another reason }\end{array}$ & 2 & 2.2 & 14 & 7.7 & 16 & 5.7 \\
\hline
\end{tabular}

BD: Bipolar Disorder; MDD: Major Depressive Disorder; BPD: Borderline Personality Disorder; SPQ-B: Schizotypal Personality Questionnaire-Brief; MSI: McLean Screening Instrument. 
$43.7 \pm 12.7$ years). Among patients with BD, 36 (36.3\%) had type I, 55 (55.5\%) type II and 8 ( $8 \%$ ) unspecified type. In terms of age and gender, sample distribution did not differ from patients with the same diagnoses treated in 2011 and 2012 in psychiatric care organizations.

\subsection{McLean Screening Instrument (MSI)}

The MSI is a ten-item questionnaire designed according to DSM-IV diagnostic criteria to screen for BPD [35]. It has been translated into Finnish and validated in Finland [36]. Each item requires a "yes/no" response. Each positive item indicates the presence of BPD symptoms. Previous research has suggested that a useful clinical cut-off score in predicting BPD among adults is seven or more [35]. Kuder-Richardson 20 (KR-20) coefficient for MSI was 0.747 . According to previous factor analysis of DSM-IV criteria of BPD [41], we allocated items into three groups: "disrupted relatedness" (including items "troubled relationships", "identity disturbance", "feeling of emptiness", "distrustfulness" and "dissociative symptoms"), "behavioural dysregulation" (i.e. "impulsivity" and "suicidal behaviour") and "affective dysregulation" (i.e. "mood instability", "increased anger" and "avoidance of abandonment").

\subsection{Schizotypal Personality Questionnaire-Brief form (SPQ-B)}

The SPQ-B is a 22-item self-report instrument derived from the 74-item SPQ-B questionnaire designed according to DSM-III-R diagnostic criteria for SPD [37]. Each positive item indicates the presence of SPD symptoms. Items were created to measure three dimensions of SPD: 8 items for cognitive-perceptual (i.e. ideas of reference, odd beliefs, magical thinking, unusual perceptual experiences, suspiciousness and paranoid ideation), 8 items for interpersonal (i.e. suspiciousness, inappropriate or constricted affect, lack of close friends and excessive anxiety) and 6 items for disorganization (i.e. odd thinking/speech and odd or eccentric behaviour/appearance) [42]. Previous research has shown 17 to be a feasible cut-off score [43]. KR-20 coefficient for SPQ-B total score was 0.857 and separately for cognitive-perceptual 0.651 , for interpersonal 0.807 and for disorganization 0.735 .

\subsection{Other scales}

The Beck Depressive Inventory (BDI) [44] is a self-report instrument designed to assess and detect the severity of current depressive symptoms in clinical, medical, and community settings. It contains 21 descriptive statements regarding depressive symptoms frequently reported by individuals diagnosed with depression. Each of the items contains a 4-point severity-rating scale. It was validated in Finland [45], Cronbach's alpha for BDI total score was 0.919. The Overall Anxiety Severity and Impairment Scale (OASIS) [46] is a brief, 5-item self-report questionnaire to assess frequency, severity and impairment associated with anxiety. The questionnaire includes five questions regarding the frequency and severity of anxiety symptoms as well as anxiety-related avoidance behaviour and decreased functioning at home/work/school and in social life. Responses range from zero to four. A recommended cut-off score for screening of anxiety disorder is 8 [47]. Chronbach's alpha for OASIS in the total sample was 0.80 .

\subsection{Statistical analysis}

The correlation analysis was executed between scales' total scores, their factors and items. Spearman's correlation coefficient was estimated between continuous variables. The phi-coefficient was calculated for binary variables and the point biserial coefficient for dichotomous and continuous variables. A correlation from 0.8 to 1 was considered as "very strong", from 0.6 to 0.79 as "strong", from 0.40 to 0.59 as "moderate", from 0.20 to 0.39 as "weak" and less than 0.2 as "very weak" [48]. The MANOVA test was used to detect the effect of age and gender on the MSI and SPQ-B scores. A separate ANOVA was conducted for each dependent variable (MSI and SPQ-B score) at an alpha level of 0.025 . In hierarchical multivariate regression (HMR) analysis with dependent variables total scores of MSI the following predictors were used model 1 (age, sex), model 2 (OASIS, BDI) and models 3 (SPQ-B score). In the HMR with dependent variable SPQ-B model 1 (age, sex), model 2 (OASIS, BDI) and model 3 (MSI) score were used. The correlation analysis, MANOVA and HMR were conducted by using SPSS version 22.0 [49].

\section{Results}

\subsection{SPQ-B and MSI scores}

No significant differences emerged in the results of screening by MSI and SPQ-B between the diagnostic groups (Table 2). However, 41.5\% ( $n=117$ ) of patients with mood disorders scored positively on the MSI and only $11 \%(n=30)$ scored positively on the SPQ-B. A strong significant correlation ( $r$ ho $=0.616, P<0.005$ ) was found between the SPQ-B and MSI total scores. The prevalence of items of both scales is reported in supplement Tables 1 and 2 .

\subsection{Factor-by-factor correlations}

The MSI dimension "disrupted relatedness" correlated moderately (rho ranged from 0.501 to $0.537 ; P<0.05$ ) with all three factors of the SPQ-B. The MSI dimension "affective dysregulation" correlated moderately with "disorganized" and "cognitive-perceptual" factors of the SPQ-B (rho $=0.440$ and 0.408 , respectively; $P<0.05)$. The MSI items "behavioural dysregulation" correlated

Table 2

Results of SPQ and MSI screening questionnaires in patients $(n=282)$.

\begin{tabular}{|c|c|c|c|c|c|}
\hline & & MDD & $\mathrm{BD}$ & Total & $P^{*}$ \\
\hline \multirow{6}{*}{$\begin{array}{l}\text { SPQ-B } \\
\text { Total scores }\end{array}$} & Mean \pm SD & $9.6 . \pm 5.2$ & $9.3 \pm 5.4$ & $9.5 \pm 5.3$ & 0.714 \\
\hline & Median & 9 & 8 & 9 & \\
\hline & $\begin{array}{l}\text { Percentile } \\
10\end{array}$ & 2 & 2 & 2 & \\
\hline & 25 & 6 & 5 & 5 & \\
\hline & 75 & 14 & 14 & 14 & \\
\hline & 90 & 17 & 17 & 17 & \\
\hline \multirow{6}{*}{$\begin{array}{l}\text { MSI } \\
\text { Total scores }\end{array}$} & Mean \pm SD & $5.5 \pm 2.7$ & $6.0 \pm 2.5$ & $5.6 \pm 2.6$ & 0.134 \\
\hline & $\begin{array}{l}\text { Median } \\
\text { Percentile }\end{array}$ & 6 & 6 & 6 & \\
\hline & 10 & 2 & 2 & 2 & \\
\hline & 25 & 3 & 4 & 4 & \\
\hline & 75 & 8 & 8 & 8 & \\
\hline & 90 & 9 & 9 & 9 & \\
\hline $\begin{array}{l}\text { SPQ-B screen } \\
\text { positive }\end{array}$ & $n(\%)$ & $18(10)$ & $12(13)$ & $30(11)$ & 0.363 \\
\hline $\begin{array}{l}\text { SPQ-B screen } \\
\text { negative }\end{array}$ & $n(\%)$ & 167 (90) & $81(87)$ & 252 (90) & 0.363 \\
\hline $\begin{array}{c}\text { MSI screen } \\
\text { positive }\end{array}$ & $n(\%)$ & $73(40)$ & $44(45)$ & $117(41.5)$ & 0.152 \\
\hline $\begin{array}{c}\text { MSI screen } \\
\text { negative }\end{array}$ & $n(\%)$ & $112(60)$ & $53(55)$ & 165 (58.5) & 0.152 \\
\hline
\end{tabular}

BD: Bipolar Disorder; MDD: Major Depressive Disorder; SD: Standard Deviation; SPQ-B: Schizotypal Personality Questionnaire-Brief; MSI: McLean Screening Instrument.

* $P$-values reflect differences between group of patients with bipolar disorder and groups of patients with major depressive disorder. 


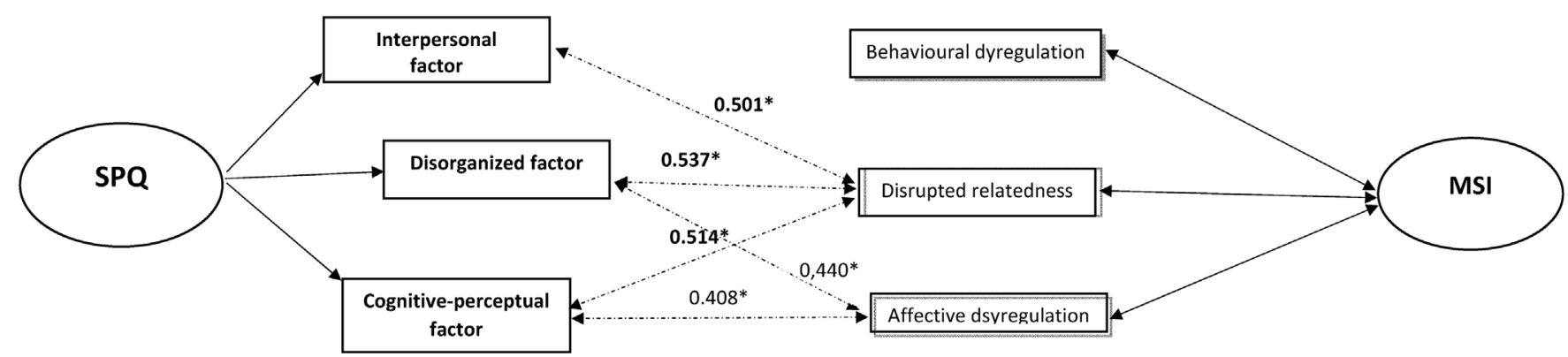

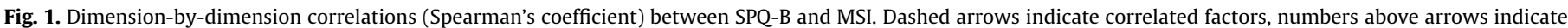
rho-values $\left({ }^{*} P<0.05\right)$. SPQ-B: Schizotypal Personality Questionnaire-Brief; MSI: McLean Screening Instrument.

only weakly (rho $=0.2 ; P<0.05$ ) with the "interpersonal" factor of the SPQ-B (Fig. 1).

\subsection{Item-by-factor correlations}

The MSI items "increased anger", "distrustfulness" and "identity disturbance" correlated moderately with all three factors of the SPQ-B. The $\mathrm{r}_{\mathrm{pb}}$-value varied from 0.3 to $0.5(P>0.005)$. The MSI items "mood instability" and "dissociative symptoms" correlated moderately $(P>0.05)$ with the "disorganized" and "cognitive-perceptual" factors of the SPQ-B. However, other items of the MSI did not correlate with factors of the SPQ-B or correlated only weakly ( $\mathrm{r}_{\mathrm{pb}}$ varied from 0.1 to $0.2 ; P<0.05$ ) (Fig. 2 ).

\subsection{Item-by-item correlations}

The MSI items "increased anger", "feeling of emptiness", "distrustfulness", "dissociative symptoms", "mood instability" and "identity disturbance" had moderate correlations with specific items of the SPQ-B $(P>0.05)$, whereas the items "troubled relationships", "suicidal behaviour", "impulsivity" and "fear of abandonment" did not correlate with SPQ-B items. The items "astrology; seeing the future; UFO", "people find me aloof and distant", "tend to keep in the background" and "special signs for you" of the SPQ-B did not correlate with MSI items at all (Table 3).

\subsection{Multivariate analysis of variance}

There was not significant differences between males and females neither on the MSI score $F(1,292)=1.38, P=0.242$, partial $\eta^{2}=0.005$; nor on the SPQ-B score $F(1,292)=1.87, P=0.172$, partial $\eta^{2}=0.006$. There were not significant differences in terms of age neither on the MSI score $\mathrm{F}(49,244)=1.48, P=0.029$, partial $\eta^{2}=0.229$ nor on the SPQ-B score $\mathrm{F}(49,244)=0.94, P=0.585$, partial $\eta^{2}=0.159$.

\subsection{Multivariate hierarchical regression analysis}

With dependent variable MSI scores models 1 (age and sex) $\mathrm{R}^{2}=0.085, \mathrm{~F}(2,278)=12.8 ., P<0.001$; adjusted $\mathrm{R}^{2}=0.078$, only variable age had significant weighs $(\beta=-0.058)$. The addition of BDI and OASIS (Model 2-age, sex, OASIS, BDI) led to a statistically significant increase in $\mathrm{R}^{2}$ of $0.177, \mathrm{~F}(4,276)=24.4, P<0.001$ with significant weights of age, OASIS and BDI $(\beta=-0.051 ; 0.165$ and

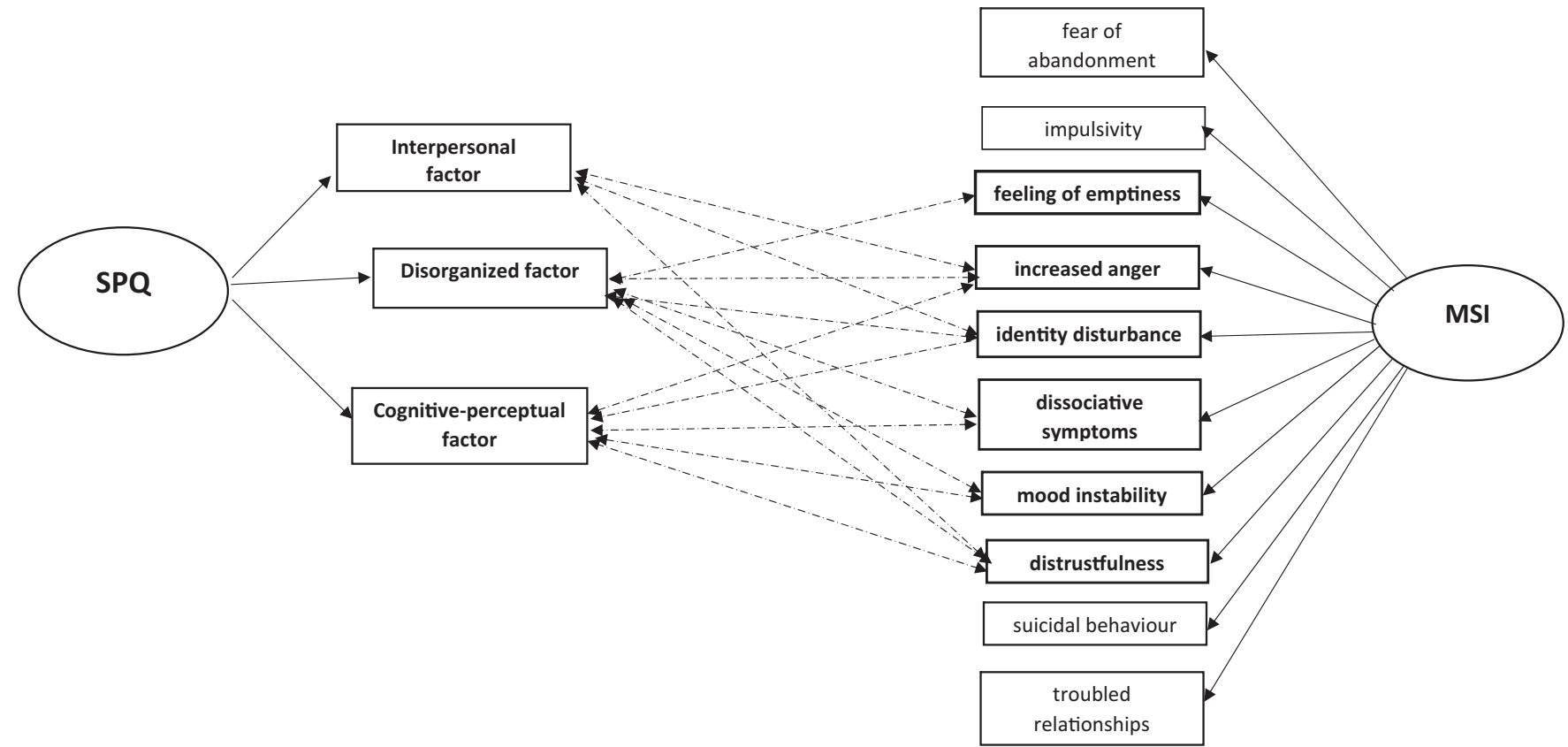

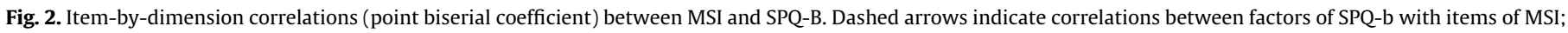
$r_{p b}$ not shown. SPQ-B: Schizotypal Personality Questionnaire-Brief; MSI: McLean Screening Instrument. 
Table 3

Item-by-item correlations (phi-coefficient) between SPQ-B and MSI in patients with mood disorders $(n=282)$.

\begin{tabular}{|c|c|c|c|c|c|c|c|c|c|c|}
\hline \multirow[t]{2}{*}{ SPQ-B } & \multicolumn{10}{|l|}{ MSI } \\
\hline & $\begin{array}{l}\text { Troubled } \\
\text { relationships }\end{array}$ & $\begin{array}{l}\text { Suicidal } \\
\text { behaviour }\end{array}$ & Impulsivity & $\begin{array}{l}\text { Mood } \\
\text { instability }\end{array}$ & $\begin{array}{l}\text { Increased } \\
\text { anger }\end{array}$ & Distrustfulness & $\begin{array}{l}\text { Dissociative } \\
\text { symptoms }\end{array}$ & $\begin{array}{l}\text { Feeling of } \\
\text { emptiness }\end{array}$ & $\begin{array}{l}\text { Identity } \\
\text { disturbance }\end{array}$ & $\begin{array}{l}\text { Fear of } \\
\text { abandonment }\end{array}$ \\
\hline $\begin{array}{l}\text { People find me aloof } \\
\text { and distant }\end{array}$ & 0.093 & 0.069 & -0.011 & 0.013 & 0.106 & $0.180^{* *}$ & 0.058 & $0.217^{* *}$ & 0.102 & 0.020 \\
\hline $\begin{array}{l}\text { Sense some person } \\
\text { or force }\end{array}$ & -0.068 & 0.029 & 0.113 & 0.107 & 0.081 & $0.163^{* *}$ & $0.277^{* *}$ & 0.094 & 0.068 & $0.124^{*}$ \\
\hline $\begin{array}{l}\text { Unusual mannerisms } \\
\text { and habits }\end{array}$ & $0.140^{*}$ & $0.192^{* *}$ & $0.191^{* *}$ & $0.281^{* * *}$ & $0.249^{* *}$ & $0.187^{* *}$ & $0.214^{* *}$ & $0.152^{* *}$ & $0.189^{* *}$ & $0.141^{*}$ \\
\hline $\begin{array}{c}\text { People can tell what } \\
\text { you are thinking }\end{array}$ & 0.056 & 0.037 & 0.067 & $0.133^{*}$ & $0.178^{*}$ & $0.131^{*}$ & $0.232^{* *}$ & 0.084 & $0.158^{* *}$ & $0.152^{* *}$ \\
\hline $\begin{array}{l}\text { Noticed special things } \\
\text { for you }\end{array}$ & -0.033 & 0.080 & 0.061 & 0.086 & 0.186 & $0.155^{*}$ & $0.163^{* * *}$ & 0.049 & $0.139^{* *}$ & $0.175^{*}$ \\
\hline $\begin{array}{l}\text { People think I am } \\
\text { very bizarre }\end{array}$ & $0.134^{*}$ & $0.085^{* *}$ & $0.185^{* *}$ & $0.272^{* * *}$ & $0.250 *$ & $0.211^{*}$ & $0.260 *$ & $0.278^{* *}$ & $0.338^{* *}$ & $0.139^{* *}$ \\
\hline $\begin{array}{l}\text { On my guard even } \\
\text { with friends }\end{array}$ & $0.183^{* *}$ & 0.085 & $0.160^{* *}$ & $0.305^{* *}$ & $0.258^{* *}$ & $0.412^{* *}$ & $0.284^{* *}$ & $0.282^{* *}$ & $0.399^{* *}$ & $0.175^{* *}$ \\
\hline $\begin{array}{l}\text { People find me vague } \\
\text { and elusive }\end{array}$ & 0.084 & 0.100 & $0.135^{* *}$ & $0.209^{* *}$ & $0.210 * *$ & $0.3366^{* *}$ & $0.174^{* *}$ & $0.230^{* *}$ & $0.308^{* *}$ & 0.067 \\
\hline $\begin{array}{l}\text { Often pick up hidden } \\
\text { threats }\end{array}$ & $0.139^{* *}$ & $0.163^{*}$ & $0.153^{* *}$ & $0.160^{*}$ & $0.218^{* *}$ & 0.290 & $0.262^{*}$ & $0.249^{* *}$ & $0.339^{* * *}$ & $0.185^{* * *}$ \\
\hline $\begin{array}{l}\text { People are taking } \\
\text { notice of me }\end{array}$ & 0.082 & $0.220^{* *}$ & $0.185^{* *}$ & $0.248^{* *}$ & $0.298^{* *}$ & $0.367^{* *}$ & $0.243^{* *}$ & $0.227^{* *}$ & $\mathbf{0 . 3 1 7} 7^{* *}$ & 0.101 \\
\hline $\begin{array}{l}\text { Discomfort with } \\
\text { unfamiliar people }\end{array}$ & $0.222^{* *}$ & $0.156^{* *}$ & $0.127^{* *}$ & $0.179^{* *}$ & $0.238^{* *}$ & $0.286{ }^{* *}$ & $0.233^{* *}$ & $0.268^{* *}$ & $0.290 * *$ & 0.112 \\
\hline $\begin{array}{l}\text { Astrology; seeing the } \\
\text { future; UFOs }\end{array}$ & 0.020 & -0.025 & 0.054 & 0.106 & 0.064 & 0.035 & 0.138 & -0.04 & 0.033 & 0.094 \\
\hline $\begin{array}{l}\text { I use words in } \\
\text { unusual ways }\end{array}$ & 0.091 & $0.131^{* *}$ & $0.261^{* *}$ & 0.276 & $0.158^{* *}$ & $0.167^{* *}$ & $0.176^{* *}$ & $0.133^{* *}$ & $0.210^{* *}$ & 0.116 \\
\hline $\begin{array}{l}\text { Not let people know } \\
\text { about you }\end{array}$ & $0.136^{*}$ & 0.023 & 0.119 & $0.139^{*}$ & 0.250 & $0.343^{* *}$ & $0.147^{*}$ & $0.174^{* *}$ & $0.221^{* *}$ & 0.028 \\
\hline $\begin{array}{l}\text { Tend to keep in the } \\
\text { background }\end{array}$ & 0.109 & 0.037 & -0.015 & 0.022 & $0.186^{* *}$ & $0.168^{* *}$ & $0.099^{*}$ & $0.154^{* *}$ & $0.221^{* *}$ & -0.050 \\
\hline $\begin{array}{l}\text { Suddenly distracted } \\
\text { by distant sounds }\end{array}$ & $0.142^{* *}$ & 0.100 & $0.190^{* * *}$ & $0.187^{* *}$ & $0.230^{* *}$ & $0.255^{* *}$ & $0.276{ }^{* *}$ & $0.184^{* *}$ & $0.239^{* *}$ & 0.092 \\
\hline $\begin{array}{l}\text { Stop people from } \\
\text { taking advantage }\end{array}$ & $0.149^{*}$ & $0.190^{* *}$ & $0.183^{* *}$ & $0.267^{* *}$ & $0.256{ }^{* *}$ & $0.319 * *$ & $0.256{ }^{* *}$ & $0.266^{* *}$ & $0.381^{* *}$ & $0.183^{* *}$ \\
\hline Unable to get close & $0.192^{* *}$ & $0.087^{*}$ & 0.049 & $0.134^{*}$ & $0.118^{* *}$ & $0.186^{*}$ & 0.088 & $0.161^{*}$ & 0.303 & $0.108^{*}$ \\
\hline $\begin{array}{l}\text { I am an odd, unusual } \\
\text { person }\end{array}$ & $0.184^{* *}$ & $0.193^{* *}$ & $0.165^{* *}$ & $0.291^{* *}$ & $0.260 * *$ & $0.228^{* *}$ & $0.355^{* *}$ & 0.223 & $0.437^{* *}$ & $0.114^{* *}$ \\
\hline $\begin{array}{l}\text { It is hard to } \\
\text { communicate clearly }\end{array}$ & 0.073 & $0.126^{* *}$ & $0.163^{* *}$ & $0.192^{* *}$ & $0.220 * *$ & $0.278^{* *}$ & $0.157^{* * *}$ & $0.276 * *$ & $0.388^{* *}$ & 0.055 \\
\hline $\begin{array}{l}\text { Very uneasy talking } \\
\text { to other people }\end{array}$ & $0.146^{* *}$ & $0.176^{* *}$ & 0.095 & 0.113 & $0.265^{* *}$ & $0.299^{* * *}$ & $0.197^{* *}$ & $0.202^{* *}$ & $0.307^{* *}$ & 0.057 \\
\hline $\begin{array}{l}\text { I tend to keep feelings } \\
\text { to myself }\end{array}$ & $0.089^{*}$ & 0.073 & 0.010 & 0.060 & $0.109^{*}$ & $0.175^{*}$ & $0.119^{*}$ & $0.143^{*}$ & $0.187^{*}$ & 0.012 \\
\hline
\end{tabular}

Bold text indicates $r_{\varphi} \geq 0.20$. SPQ-B: Schizotypal Personality Questionnaire-Brief; MSI: McLean Screening Instrument.

${ }^{*} P<0.05$.

** $P<0.005$

0.070 , respectively). The addition of SPQ-B (Model 3-age, sex, OASIS, BDI, SPQ-B) led to a statistically significant increase in $\mathrm{R}^{2}$ of $0.191, F(5,275)=45.4, P<0.001$ with significant weights of age, OASIS, SPQ-B ( $\beta=-0.039 ; 0.102 ; 0.263$, respectively).

With dependent variable SPQ-B scores models 1 (age and sex) $\mathrm{R}^{2}=0.027, \mathrm{~F}(2,278)=3.9$., $P<0.001$; adjusted $\mathrm{R}^{2}=0.020$, only variable age had significant weighs $(\beta=-0.062)$. The addition of BDI and OASIS (Model 2-age, sex, OASIS, BDI) led to a statistically significant increase in $\mathrm{R}^{2}$ of $0.269, \mathrm{~F}(4,276)=29.1, P<0.001$ with significant weights of age, sex OASIS and BDI $(\beta=-0.044 ;-1.55$; 0.240 and 0.199 , respectively). The addition of MSI (Model 3-age, sex, OASIS, BDI, MSI) led to a statistically significant increase in $\mathrm{R}^{2}$ of $0.182, \mathrm{~F}(5,275)=50.4, P<0.001$ with significant weights of sex, BDI, MSI $(\beta=-1.6 ; 0.131 ; 0.983$, respectively).

\subsection{Correlation analysis between scores SPQ-B and BDI scores}

A significant moderate correlation ( $r$ ho $=0.498 ; P<0.005$ ) was present between total scores of SPQ-B and BDI. In score-by-item correlations, "on my guard even with friends", "people are taking notice of you", "often pick up hidden threats", "tend to keep feelings to myself", "very uneasy talking to people" and "tend to keep in the background" correlated moderately with total scores of BDI $\left(\mathrm{r}_{\mathrm{pb}}\right.$ varied from 0.403 to $\left.0.495 ; P<0.005\right)$.

\section{Discussion}

We found self-reported symptoms of BPD and SPD to be prevalent among patients with mood disorders treated in psychiatric specialized units. We also demonstrated a strong correlation between total scores of self-reported SPD symptoms on the Schizotypal Personality Questionnaire-Brief (SPQ-B) and those of BPD on the MSI. Moreover, we investigated overlapping and non-overlapping self-reported features of BPD and SPD at the level of both dimensions and separate items of the MSI and SPQ-B.

To our knowledge, this is the first study examining features and phenomenological overlap between SPD and BPD based on the self-report screening instruments MSI and SPQ-B in mood disorder patients. A strength of our study was in the relatively large number 
of mood disorder patients recruited from specialized psychiatric care. Moreover, extensive data of self-reported symptoms of BPD and SPD were collected. There were also several limitations.

- the response rate was 35\%, likely due to the survey being conducted in busy routine service facilities. Nevertheless, the analysis of representativeness indicated no significant differences in terms of age or sex between our cohort and the whole population of patients treated in the years 2011 and 2012;

- only patients with mood disorders were included in our study, which may limit the generalizability of our findings;

- the clinical diagnoses were not verified with structured clinical diagnostic interview instruments. However, all patients had been diagnosed with mood disorders in psychiatric settings specialized in their treatment, and all available diagnostic information was re-evaluated by the authors. Furthermore, the focus of this study was on responses to the MSI and SPQ-B questionnaires, not diagnoses of mood disorders, BPD or SPD per se;

- the focus of study was on self-reported symptoms, which can be influenced by impairments in patients' self-reflection and cognition; no scales of desirability or infrequency were used;

- the study was observational, and possible influences of treatment could not be controlled.

Overall, self-reported features of BDP and SPD in patients with mood disorders were prevalent. However, prevalence of features of BPD was more noticeable than features of SPD in mood disorder patients. In comparison with previous studies using the SPQ-B and MSI in student and adolescent populations, patients with mood disorders received a similar mean total score of SPQ-B [42,50], but a higher mean MSI [51,52]. Thus, self-reported features of BPD appear to be more prevalent in patients with mood disorders than in student populations, whereas no differences in self-reported features of SPD exist between mood disorder patients and student populations.

The significant overlap between symptoms of BPD and SPD at both clinical and subclinical levels has been the topic of numerous discussions after their separation in the DSM-III-R [1,3,17,18,53-56]. We found strong correlations between total scores of the screening instruments SPQ-B and MSI, indicating considerable overlap in self-reported features of BPD and SPD. Moreover, we indicated overlapping and not-overlapping items and their clusters. Specifically, the MSI items of "identity disturbance", "distrustfulness" and "increased anger" correlated with all dimensions of the SPQ-B. Additionally, the MSI items of "dissociative symptoms", "mood instability" and "feeling of emptiness" correlated moderately with disorganized and cognitive-perceptual dimensions of the SPQ-B. By contrast, the MSI items reflecting behavioural dysregulation (i.e. "suicidal behaviour" and "impulsivity") and "fear of abandonment" correlated only weakly or did not correlate at all. At the same time, SPQ-B items "astrology, seeing the future, UFO", "people find me aloof and distant", "tend to keep in the background" and "special signs for you" did not correlate with MSI items.

Cognitive-perceptual distortions are one of the core features of SPD [14,57]. However, they can also be observed in patients with BPD [14]. Transient psychotic-like and dissociative symptoms related to affective shifts (such as intense anger, anxiety and disappointment) associated with the fear of abandonment and interpersonal disputes are frequent in BPD also [31,58-60]. We suggest that the partial overlap of symptoms of BPD and SPD may underlie the high correlation between such self-reported features of BPD as "mood instability", "increased anger", "distrustfulness" "identity disturbance" and "dissociative symptoms" and some specific symptoms of SPD. However, paranoid ideations, illusions and dissociative symptoms in patients with BPD are usually transient and triggered by extreme stress in response to a real or imagined abandonment. In contrast, cognitive-perceptual distortions in patients with SPD are more enduring and less associated with pronounced affective symptoms [14]. However, neither of the two questionnaires contains information on duration of symptoms or role of triggering factors for dissociative symptoms. As a result, patients with different types of cognitive-perceptual distortions may answer "yes" to specific questions on both questionnaires, potentially leading to false interpretations of BPD or SPD. Therefore, comprehensive clinical interviews are indispensable for diagnosis.

The result of screening instruments is based on the patient's own estimation of the presence or absence of symptoms. Different factors may influence a patient's ability to answer to the scale's questions, including previously described impairments in social cognition [61,62], autobiographical memory disruptions [63], current mood, and co-morbid anxiety disorders, among others. In our study, we revealed a significant effect of anxiety symptoms on MSI score and, conversely, depressive symptoms significantly predicted SPQ-B score. Moreover, we showed that SPQ-B items reflecting cognitive-perceptual and interpersonal groups of symptoms of SPD particularly correlated with depressive symptoms. This may indicate that higher severity of current symptoms of depression may complicate distinguishing between self-reported features of SPD in patients with mood disorders.

Despite this overlap, other items appear to contain more specific features of each disorder. For instance, symptoms of BPD reflecting behavioural dysregulation (i.e. "impulsivity" and "suicidal behaviour") and some symptoms of disrupted relatedness (i.e. "fear of abandonment", "troubled relationships" and "feeling of emptiness") and such symptoms of SPD as "astrology, seeing the future, UFO", "people find me aloof and distant" and "tend to keep in the background" appeared to be nonoverlapping and are therefore more specific for the core nature of psychopathology of both disorders. Non-overlapping features may be essential in differentiating symptoms of BPD and SPD. Using the self-report questionnaires MSI and SPQ-B, it is likely important to evaluate how a patient's answers are distributed between overlapping and non-overlapping symptoms of BPD and SPD. This can support clinicians in a more accurate comprehensive clinical interview intended to distinguishing between BPD and SPD.

\section{Conclusions}

A partial overlap in the psychopathology of BPD and SPD can be observed at the level of self-reported features. Particularly, items reflecting cognitive-perceptual distortions and affective symptoms of BPD appear to overlap with some symptoms of SPD, making it difficult to distinguish between the two disorders. However, items reflecting behavioural dysregulation in patients with BPD and those reflecting social detachment and perceptual alterations in patients with SPQ-B appear to be more specific to each personality disorder. Nevertheless, symptoms of co-morbid depression may aggravate the self-reported features of SPD, and likewise, symptoms of anxiety the self-reported features of BPD. A more detailed clinical interview is needed to differentiate the symptoms of each disorder.

\section{Disclosure of interest}

The authors declare that they have no competing interest. 
Appendix A. Supplementary data

Supplementary data associated with this article can be found, in the online version, at http://dx.doi.org/10.1016/j.eurpsy.2015.12. 006.

\section{References}

[1] Gunderson JG, Singer MT. Defining borderline patients: an overview. Am J Psychiatry 1975;132(1):1-10

[2] Spitzer RL, Endicott J. Justification for separating schizotypal and borderline personality disorders. Schizophr Bull 1979;5(1):95-104

[3] Gunderson JG, Zanarini MC. Current overview of the borderline diagnosis. J Clin Psychiatry 1987;Suppl. 48:5-14.

[4] American Psychiatric Association, editor. Diagnostic and statistical manual of mental disorders. third edition revised. III ed., Washington, DC; 1987.

[5] Kwapil TR, Barrantes-Vidal N. Schizotypy: looking back and moving forward. Schizophr Bull 2015;41(Suppl. 2):S366-73.

[6] Siever LJ, Gunderson JG. The search for a schizotypal personality: historical origins and current status. Compr Psychiatry 1983;24(3):199-212.

[7] Gunderson JG. Borderline personality disorder: ontogeny of a diagnosis. Am J Psychiatry 2009;166(5):530-9.

[8] Grant BF, Chou SP, Goldstein RB, Huang B, Stinson FS, Saha TD, et al. Prevalence, correlates, disability, and comorbidity of DSM-IV borderline personality disorder: Results from the wave 2 national epidemiologic survey on alcohol and related conditions. J Clin Psychiatry 2008;69(4):533-45.

[9] Critchfield KL, Clarkin JF, Levy KN, Kernberg OF. Organization of co-occurring axis II features in borderline personality disorder. Br J Clin Psychol 2008;47(Pt 2): 185-200.

[10] Silk KR, Westen D, Lohr NE, Benjamin J, Gold L. DSM-III and DSM-III-R schizotypal symptoms in borderline personality disorder. Compr Psychiatry 1990;31(2):103-10.

[11] Becker DF, Grilo CM, Edell WS, McGlashan TH. Comorbidity of borderline personality disorder with other personality disorders in hospitalized adolescents and adults. Am J Psychiatry 2000;157(12):2011-6.

[12] Pulay AJ, Stinson FS, Dawson DA, Goldstein RB, Chou SP, Huang B, et al. Prevalence, correlates, disability, and comorbidity of DSM-IV schizotypal personality disorder: Results from the wave 2 national epidemiologic survey on alcohol and related conditions. Prim Care Companion J Clin Psychiatry 2009;11(2):53-67.

[13] Mohr C, Claridge G. Schizotypy-do not worry, it is not all worrisome. Schizophr Bull 2015;41(Suppl. 2):S436-43.

[14] American Psychiatric Association. The diagnostic and statistical manual of mental disorders, 5th ed., 2013.

[15] Badoud D, Billieux J, Eliez S, Imhof A, Heller P, Eytan A, et al. Covariance and specificity in adolescent schizotypal and borderline trait expression. Early Interv Psychiatry 2015;9(5):378-87.

[16] Benedik E, Dobnik SC. Phemenological aspects of personality disorders in adult psychiatric patients. Psychiatr Danub 2014;26(2):127-36.

[17] Plakun EM, Muller JP, Burkhardt PE. The significance of borderline and schizotypal overlap. Hillside J Clin Psychiatry 1987;9(1):47-54.

[18] Rosenberger PH, Miller GA. Comparing borderline definitions: DSM-III borderline and schizotypal personality disorders. J. Abnorm Psychol 1989;98(2): 161-9.

[19] Fonseca-Pedrero E, Lemos-Giraldez S, Paino M, Sierra-Baigrie S, Muniz J. Relationship between schizotypal and borderline traits in college students. Span J Psychol 2012;15(1):306-14.

[20] Melartin TK, Haukka J, Rytsala HJ, Jylha PJ, Isometsa ET. Categorical and dimensional stability of comorbid personality disorder symptoms in DSMIV major depressive disorder: A prospective study. J Clin Psychiatry 2010; 71(3):287-95.

[21] McGlashan TH, Grilo CM, Sanislow CA, Ralevski E, Morey LC, Gunderson JG, et al. Two-year prevalence and stability of individual DSM-IV criteria for schizotypal, borderline, avoidant, and obsessive-compulsive personality disorders: Toward a hybrid model of axis II disorders. Am J Psychiatry 2005; 162(5):883-9.

[22] Stringer B, van Meijel B, Eikelenboom M, Koekkoek B, Licht CM, Kerkhof AJ, et al. Recurrent suicide attempts in patients with depressive and anxiety disorders: the role of borderline personality traits. J Affect Disord 2013;151(1): 23-30.

[23] Skodol AE, Grilo CM, Pagano ME, Bender DS, Gunderson JG, Shea MT, et al. Effects of personality disorders on functioning and well-being in major depressive disorder. J Psychiatr Pract 2005;11(6):363-8.

[24] Skodol AE, Grilo CM, Keyes KM, Geier T, Grant BF, Hasin DS. Relationship of personality disorders to the course of major depressive disorder in a nationally representative sample. Am J Psychiatry 2011;168(3):257-64.

[25] Jylha P, Melartin T, Rytsala H, Isometsa E. Neuroticism, introversion, and major depressive disorder-traits, states, or scars? Depress Anxiety 2009;26(4): 325-34.

[26] Reich J, Noyes Jr R, Coryell W, O'Gorman TW. The effect of state anxiety on personality measurement. Am J Psychiatry 1986;143(6):760-3.

[27] Morey LC, Shea MT, Markowitz JC, Stout RL, Hopwood CJ, Gunderson JG, et al. State effects of major depression on the assessment of personality and personality disorder. Am J Psychiatry 2010;167(5):528-35.
[28] Karsten J, Penninx BW, Riese H, Ormel J, Nolen WA, Hartman CA. The state effect of depressive and anxiety disorders on big five personality traits. J Psychiatr Res 2012;46(5):644-50.

[29] Rosell DR, Futterman SE, McMaster A, Siever LJ. Schizotypal personality disorder: A current review. Curr Psychiatry Rep 2014;16(7):452. doi: 0140452-1.

[30] Bateman AW, Gunderson J, Mulder R. Treatment of personality disorder. Lancet 2015;385(9969):735-43.

[31] Leichsenring F, Leibing E, Kruse J, New AS, Leweke F. Borderline personality disorder. Lancet 2011;377(9759):74-84.

[32] Mason OJ. The assessment of schizotypy and its clinical relevance. Schizophr Bull 2015;41(Suppl. 2):S374-85.

[33] Tyrer P, Reed GM, Crawford MJ. Classification, assessment, prevalence, and effect of personality disorder. Lancet 2015;385(9969):717-26.

[34] Rush JA. Preface. In: Rush JA, First MB, Blacker D, editors. Handbook of Psychiatric Measures. 2nd ed., American Psychiatric Association; 2008.

[35] Zanarini MC, Vujanovic AA, Parachini EA, Boulanger JL, Frankenburg FR, Hennen J. A screening measure for BPD: the McLean screening instrument for borderline personality disorder (MSI-BPD). J Pers Disord 2003;17(6): 568-73.

[36] Melartin T, Hakkinen M, Koivisto M, Suominen K, Isometsa ET. Screening of psychiatric outpatients for borderline personality disorder with the McLean screening instrument for borderline personality disorder (MSI-BPD). Nord J Psychiatry 2009;63(6):475-9.

[37] Raine A. The SPQ: a scale for the assessment of schizotypal personality based on DSM-III-R criteria. Schizophr Bull 1991;17(4):555-64.

[38] Baryshnikov I, Aaltonen K, Koivisto M, Näätänen P, Karpov B, Melartin T, et al. Differences and overlap in self-reported symptoms of bipolar disorder and borderline personality disorder. Eur Psychiatry 2015;30(8):914-9.

[39] World Health Organization. International classification of disease, 10th ed, Geneva; 1992.

[40] American Psychiatric Association. Diagnostic and statistical manual of mental disorders, 4th ed., Washington, DC; 1994.

[41] Sanislow CA, Grilo CM, Morey LC, Bender DS, Skodol AE, Gunderson JG, et al. Confirmatory factor analysis of DSM-IV criteria for borderline personality disorder: findings from the collaborative longitudinal personality disorders study. Am J Psychiatry 2002;159(2):284-90.

[42] Compton MT, Goulding SM, Bakeman R, McClure-Tone EB. An examination of the factorial structure of the schizotypal personality questionnaire-brief (SPQ-B) among undergraduate students. Schizophr Res 2009;115(2-3):286-9.

[43] Ma WF, Wu PL, Yang SJ, Cheng KF, Chiu HT, Lane HY. Sensitivity and specificity of the Chinese version of the schizotypal personality questionnaire-brief for identifying undergraduate students susceptible to psychosis. Int J Nurs Stud 2010:47(12):1535-44

[44] Beck AT, Ward CH, Mendelson M, Mock J, Erbaugh J. An inventory for measuring depression. Arch Gen Psychiatry 1961;4:561-71.

[45] Nuevo R, Lehtinen V, Reyna-Liberato PM, Ayuso-Mateos JL. Usefulness of the beck depression inventory as a screening method for depression among the general population of Finland. Scand J Public Health 2009;37(1):28-34.

[46] Norman SB, Cissell SH, Means-Christensen AJ, Stein MB. Development and validation of an overall anxiety severity and impairment scale (OASIS). Depress Anxiety 2006;23(4):245-9.

[47] Campbell-Sills L, Norman SB, Craske MG, Sullivan G, Lang AJ, Chavira DA, et al. Validation of a brief measure of anxiety-related severity and impairment: the overall anxiety severity and impairment scale (OASIS). J Affect Disord 2009; 112(1-3):92-101.

[48] Evans JSBT, Over DE. Rationality and reasoning. Hove, England: Psychology press; 1996.

[49] IBM Corp. Released 2013. IBM SPSS statistics for windows, version 22.0. Armonk, NY: IBM Corp; 2013.

[50] Fonseca-Pedrero E, Paino-Pineiro M, Lemos-Giraldez S, Villazon-Garcia U, Muniz J. Validation of the schizotypal personality questionnaire-brief form in adolescents. Schizophr Res 2009;111(1-3):53-60.

[51] Glenn CR, Klonsky ED. Emotion dysregulation as a core feature of borderline personality disorder. J Pers Disord 2009;23(1):20-8.

[52] Leung SW, Leung F. Construct validity and prevalence rate of borderline personality disorder among Chinese adolescents. J Pers Disord 2009;23(5): 494-513.

[53] Gunderson JG. The relatedness of borderline and schizophrenic disorders. Schizophr Bull 1979;5(1):17-22.

[54] Kernberg OF. Two reviews of the literature on borderlines: An assessment. Schizophr Bull 1979;5(1):53-8.

[55] McGlashan TH. The borderline syndrome. I. Testing three diagnostic systems. Arch Gen Psychiatry 1983;40(12):1311-8.

[56] Siever LJ, Torgersen S, Gunderson JG, Livesley WJ, Kendler KS. The borderline diagnosis. III. Identifying endophenotypes for genetic studies. Biol Psychiatry 2002;51(12):964-8.

[57] Hummelen B, Pedersen G, Karterud S. Some suggestions for the DSM-5 schizotypal personality disorder construct. Compr Psychiatry 2012;53(4): $341-9$.

[58] Balaratnasingam S, Janca A. Normal personality, personality disorder and psychosis: current views and future perspectives. Curr Opin Psychiatry 2015;28(1):30-4.

[59] Barnow S, Arens EA, Sieswerda S, Dinu-Biringer R, Spitzer C, Lang S. Borderline personality disorder and psychosis: A review. Curr Psychiatry Rep 2010;12(3): 186-95. 
[60] Dowson JH, Sussams P, Grounds AT, Taylor J. Associations of self-reported past "psychotic" phenomena with features of personality disorders. Comp Psychiatry 2000;41(1):42-8.

[61] Preissler S, Dziobek I, Ritter K, Heekeren HR, Roepke S. Social cognition in borderline personality disorder: Evidence for disturbed recognition of the emotions, thoughts, and intentions of others. Front Behav Neurosci 2010;4:182.
[62] Jahshan CS, Sergi MJ. Theory of mind, neurocognition, and functional status in schizotypy. Schizophr Res 2007;89(1-3):278-86.

[63] Kim WJ, Ha RY, Sun JY, Ryu V, Lee SJ, Ha K, et al. Autobiographical memory and its association with neuropsychological function in bipolar disorder. Compr Psychiatry 2014;55(2):290-7. 